\title{
Characteristics of Multiwall Carbon Nanotubes for an Intratracheal Instillation Study with Rats
}

\author{
Mitsutoshi TAKAYA ${ }^{1 *}$, Fumio SERITA ${ }^{1}$, Kazunori YAMAZAKI ${ }^{2}$, Shigetoshi AISO², \\ Hisayo KUBOTA ${ }^{1}$, Masumi ASAKURA ${ }^{2}$, Naoki IKAWA ${ }^{2}$, Kasuke NAGANO ${ }^{2}$, \\ Heihachiro ARITO ${ }^{2}$ and Shoji FUKUSHIMA ${ }^{2}$
}

\author{
${ }^{1}$ National Institute of Occupational Safety and Health, 6-21-1 Nagao, Tama-ku, Kawasaki, Kanagawa, \\ 214-8585, Japan \\ ${ }^{2}$ Japan Bioassay Research Center, Japan Industrial Safety and Health Association, 2445 Hirasawa, Hadano, \\ Kanagawa, 257-0015, Japan
}

Received July 23, 2009 and accepted December 3, 2009

\begin{abstract}
Much concern has been raised over the health consequences of workers exposed to carbon nanotubes. In order to characterize multi-wall carbon nanotubes (MWCNT) suspended in a phosphate-buffered saline containing $0.1 \%$ Tween 80 for an intratracheal instillation study. Length and width distributions of the MWCNT fibers, dispersion of MWCNT in the suspension and in the lung tissue and the MWCNT contents of metal impurities were investigated. Arithmetic mean length and width of the MWCNT fibers as measured on scanning electron microscope (SEM) photographs were $5.0 \mu \mathrm{m}$ and $88 \mathrm{~nm}$, respectively, and fibers longer than $5.0 \mu \mathrm{m}$ were $38.9 \%$ of all fibers measured. Dynamic light scattering size measurement revealed that 5-min ultrasonication, together with addition of Tween 80 into the suspension, decreased the hydrodynamic diameters of the agglomerated MWCNT to those of finer particles below 1.0 $\mu \mathrm{m}$. SEM observation showed good dispersion of MWCNT in the suspension, and in the alveoli on Day 1 after instillation. Concentration of iron, chromium and nickel in the MWCNT were 4,400, 48 and $17 \mathrm{ppm}$ (wt/wt), respectively, all of which were below levels that would elicit positive pulmonary toxic responses to these metals. The results suggest that well-dispersed, long and thin MWCNT fibers exhibit asbestos-like pathogenicity in the lung.
\end{abstract}

Key words: Multiwall carbon nanotube, Metal impurities, Iron, SEM, Dynamic light scattering, Size distribution, Dose characterization

\section{Introduction}

In this decade, one of the most important developed in industrial technology is nanotechnology which makes use of nano-scale $(<100 \mathrm{~nm})$ structure-controlled materials. Use of nanotechnology is expected to grow exponentially in the first half of the 21 st century. The growth of nanotechnology industries has prompted a rapid increase in amounts and kinds of nanomaterial production. However, the increased use of nanomaterials may result in new types of health risks for workers exposed to nanomaterials.

*To whom correspondence should be addressed.

E-mail: takaya@h.jniosh.go.jp
At present, health hazards of nanomaterials have not been clarified sufficiently yet, and many researchers have been extensively investigating biological responses to nanomaterials, using in vivo and in vitro techniques. Among the many types of nanomaterials, carbon nanotubes (CNT) have raised much attention and concern, since their fibrous forms are similar to those of asbestos. Recent studies by Takagi et al. ${ }^{1)}$ and Sakamoto et $a l .{ }^{2)}$ showed that mesotheliomas are induced by intraperitoneal and intrascrotal administrations of multiwall carbon nanotubes (MWCNT) in p53 gene-deficient mice and male Fischer 344 rats, respectively. Poland et $a l .{ }^{3)}$ also demonstrated the asbestos-like pathogenicity of long MWCNT fibers administered to the peritoneal cavity of female mice. Since inhalation is the primary 
route of exposure of workers to carbon nanotubes, and since the target organ is the respiratory system, use of an inhalation exposure system would be recommended for a study of experimental toxicology. Because of the technical difficulty in generating stable MWCNT aerosol at a constant concentration for an inhalation study, the technique of intratracheal instillation or pharyngeal aspiration has been extensively used to examine the pulmonary toxicity of nanomaterials in spite of the limitations of intratracheal instillation ${ }^{4)}$. Since MWCNT is agglomerated in a rope-like structure and insoluble in aqueous solutions, use of well-dispersed MWCNT fibers suspended in an aqueous solution containing a dispersant is a prerequisite in an intratracheal instillation study evaluating the pulmonary toxicity of MWCNT. Indeed, Mercer et al. ${ }^{5)}$ reported that exposure of mice to well-dispersed single-wall carbon nanotubes (SWCNT) fibers by pharyngeal aspiration affected pulmonary distribution and responses. It has also been reported that in addition to the size, shape and agglomerated state ${ }^{3,6)}$, the content of iron used for catalysis ${ }^{7-9)}$ modified the pulmonary responses of rats and mice to CNT.

In order to evaluate the pulmonary responses of rats to MWCNT by administered intratracheal instillation, information about the characteristics of MWCNT such as length and width of MWCNT fibers, dispersion of MWCNT in the suspension and in the lung tissue and metal impurities in MWCNT is of prime importance. Therefore, the present study measured the length and width of dispersed MWCNT fibers in a suspension by scanning electron microscopic (SEM) observation, to explore how to well-disperse MWCNT fibers in a suspension and in lung tissues, and to determine concentrations of metal impurities in MWCNT that might modify the pulmonary responses to MWCNT. The results of the pulmonary toxic responses of male Fischer 344 rats to the intratracheally instilled MWCNT under the same conditions of dosage as those obtained in the present study were submitted to Industrial Health as a separate paper ${ }^{10)}$.

\section{Materials and Methods}

\section{Test substance}

MWCNT used in the present study was kindly supplied by Mitsui \& Co., Ltd. (MWCNT-7, Lot No. 061220, Tokyo, Japan). This MWCNT was synthesized by the vapor phase chemical vapor deposition (CVD) and graphitization following CVD. Most manufacturers with large-scale production of MWCNT have adopted vapor phase CVD according to their published information ${ }^{11,12)}$. The MWCNT used in the present study was a typical sample of MWCNT being manufactured at present.

Size distribution and dispersion of MWCNT in the suspension

MWCNT was suspended in phosphate-buffered saline (PBS) containing $0.1 \%$ Tween 80 as a dispersant. Then, the suspension was subjected to ultrasonication with an ultrasonic homogenizer (VP-30S, $20 \mathrm{kHz}, 300 \mathrm{~W}$, TAITEC Co., Ltd, Tokyo, Japan) for various periods of time.

The size distribution of MWCNT in the suspension was evaluated by both SEM observation and dynamic light scattering size (DLS) measurement. Sample preparation for SEM observation of fibers was described in detail in our previous paper ${ }^{13)}$. Briefly, a water drop of MWCNT suspension at $533 \mu \mathrm{g} / \mathrm{ml}$ was put on a polycarbonate membrane filter (Isopore, Millipore, MA, USA) set on a suction filtration apparatus. A drop of the sample suspension was put onto another pre-settled water-drop, and the suction was started. The filtered membrane filter samples were dried in air. After drying the filter was pre-coated with Pt-Pd for electron charge avoidance, and the MWCNT fibers were observed with a field emission SEM (S-4700, Hitachi, Tokyo, Japan). Several fields of viewing were photographed at magnifications of $\times 1,000$ and $\times 5,000$ for measurement of length and width, respectively. The length and width of MWCNT fibers, almost all of which appeared to be isolatably thin in each field, were measured with a curvimeter and scale loupe on enlarged photoprints. The number of fibers used in the length and width measurements were 1,000 and 500, respectively. The DLS measurement with a Zetasizer Nano DLS analyzer (Malvern, Worcestershire, UK) was performed on the PBS-Tween 80 suspension containing MWCNT at $533 \mu \mathrm{g} / \mathrm{ml}$. In order to prevent excessive lung burden of MWCNT, we chose the level of $533 \mu \mathrm{g} / \mathrm{ml}$ which is equivalent to an intratracheally instilled dose of $160 \mu \mathrm{g} / \mathrm{rat}$, based on Morrow's report ${ }^{14)}$ that the level of dust burden causing lung overload was greater than 1-2 mg of persistently retained dust in the lungs of F344 rats.

Dispersion of MWCNT in the aerosolized suspension and in the lung

In order to observe the dispersed state of MWCNT fibers in the PBS-Tween 80 suspension exactly at the time of intratracheal instillation, the suspension containing MWCNT at $533 \mu \mathrm{g} / \mathrm{ml}$ was ejected into the air from the tip of the microspray cannula of an Intratracheal Aerosolizer (1A-1B, PennCentury, Inc., USA) which was connected to a syringe pre-filled with the MWCNT suspension. The experimental set-up for aerosolization in a glove-box is presented in Fig. 1. The aerosol- 


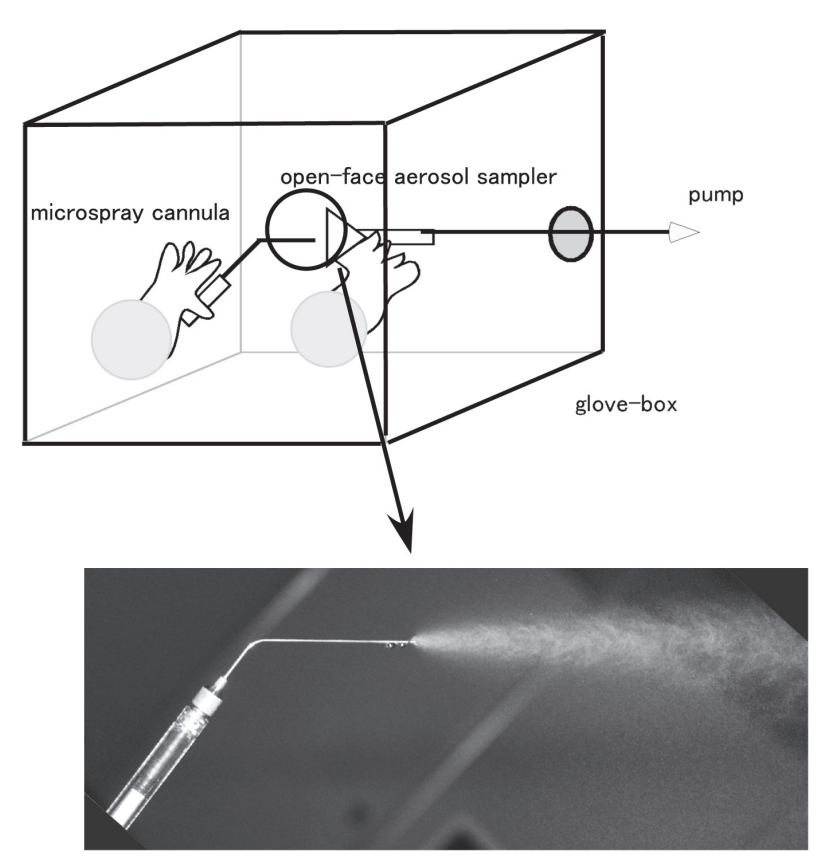

Fig. 1. The experimental set-up was installed in a glove-box (A). Aerosolized MWCNT suspension was ejected into the air from the tip of a microspray cannula which was connected with a syringe filled with the MWCNT suspension (B). The concentration of MWCNT suspension used was $533 \mu \mathrm{g} / \mathrm{ml}$ (equivalent to a dose of $160 \mu \mathrm{g}$ in $0.3 \mathrm{ml}$ suspension).

ized MWCNT suspension was collected on a 25-mm Isopore-membrane filter using an open-face aerosol sampler which was connected to a sampling pump (Lelandpump, SKC, USA). The sampling rate was $91 / \mathrm{min}$, and the distance between the filter sampler and the tip of the microspray cannula was about $20 \mathrm{~cm}$. The filter sample was dried in air, and after drying the filter was pre-coated with Pt-Pd. The sample was observed with the SEM.

In order to examine whether the well-dispersed state of the MWCNT fibers after intratracheal instillation was maintained in the lung tissues, the deposition of MWCNT in left lung tissues of the rats which received intratracheal instillation at a dose of $160 \mu \mathrm{g} / \mathrm{rat}$ was examined by SEM one day 1 after instillation ${ }^{10)}$.

\section{Analysis of metal impurities in MWCNT}

At first, the MWCNT was analyzed qualitatively for metals by Laser-Abrasion Inductively Coupled Mass Spectrometry (LA-ICP-MS). Figure 2 shows the procedure of sample preparation for LA-ICP-MS analysis. MWCNT was suspended in ethanol, and a portion of the suspension was put onto a PTFE membrane filter (Omnipore, Millipore, Billerica, MA, USA). The filter sample was fixed to a slide glass (Matsunami Glass Industry, Kishiwada, Japan) using ultraviolet cur- ing glue (Three Bond 1771E, Three bond, Hachioji, Japan), and then pressed with $500 \mathrm{~g}$ weight. The fixed particle samples were vaporized by a $213 \mathrm{~nm}$ NdYAG laser (UP-213 Electro Scientific Industry, Portland, OR, USA) and the vapor was introduced into an Inductively Coupled Plasma-Mass Spectrometer (Agilent 7500c, Yokogawa Analytical, Tokyo, Japan) for qualitative analysis of the elements.

After the qualitative analysis, the detected metal impurities were analyzed quantitatively by graphite furnace atomic absorption spectrometry (AAS) as follows. About $20 \mathrm{mg}$ of MWCNT was weighed, then the sample was digested with $5 \mathrm{ml}$ of hydrochloric acid, $2.5 \mathrm{ml}$ of nitric acid and $5 \mathrm{ml}$ water solution for $30 \mathrm{~min}$ heating at $160^{\circ} \mathrm{C}$. After cooling, the solution was diluted by $0.5 \%$ nitric acid to $50 \mathrm{ml}$. The metal concentrations in the sample solution were measured by a graphite atomic absorption spectrometer (Z-5010, Hitachi, Tokyo, Japan).

\section{Results}

\section{Length and width of MWCNT fiber}

Figure 3 shows the distribution of lengths and widths of MWCNT fibers as determined by the SEM analysis. The arithmetic mean and SD of the fiber lengths were $5.0 \pm 4.5 \mu \mathrm{m}$, ranging from $0.5 \mu \mathrm{m}$ at the minimum to $21.8 \mu \mathrm{m}$ at the maximum. The fibers with lengths greater than $5 \mu \mathrm{m}$ were $38.9 \%$ of fibers measured, indicating that the distributions of the lengths was skewed with longer fibers. The arithmetic mean and SD of the fiber width were $88 \pm 5 \mathrm{~nm}$, ranging from $40 \mathrm{~nm}$ at the minimum to $173 \mathrm{~nm}$ at the maximum.

\section{Dispersion of MWCNT fibers in the suspension and in the lung tissue}

In order to facilitate dispersion of the MWCNT fibers, Tween 80 was added at a concentration of $0.1 \%$ in the suspension in the present study. Figure 4 shows the effect of ultrasonication on MWCNT particle sizes evaluated by the DLS measurement for the hydrodynamic diameter which was numerically derived from optical measurement of the Brownian motion of the target particles, on the assumption that the particles were spherical. Five minutes ultrasonication of the MWCNT suspension was found to completely eliminate the second peak with a diameter of $7.0 \mu \mathrm{m}$, decrease the diameter of the main peak from $2.0 \mu \mathrm{m}$ to below 1.0 $\mu \mathrm{m}$, and create a new fraction of MWCNT of $0.2 \mu \mathrm{m}$ in diameter. A SEM image indicating good dispersion of the MWCNT fibers in the suspension is presented in Fig. 5A. In the simulation experiment (Fig. 1), the microspray cannula was found to completely aerosolize 


\section{1. putting MWCNT-particles onto membrane filter}

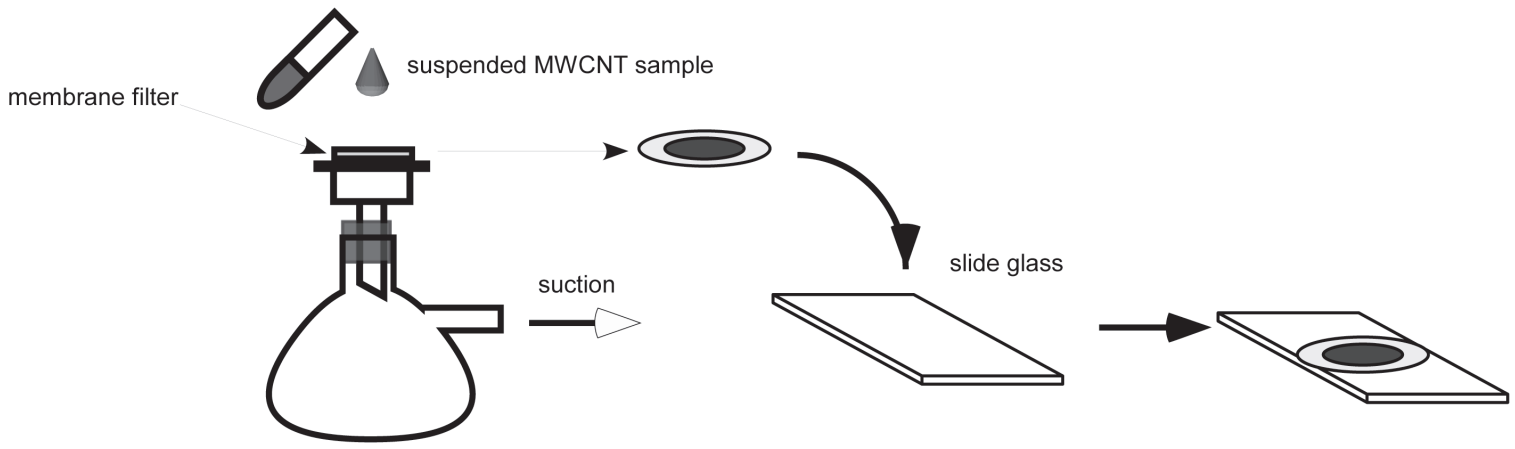

2. fixation of particles on the membrane filter with UV-curing glue

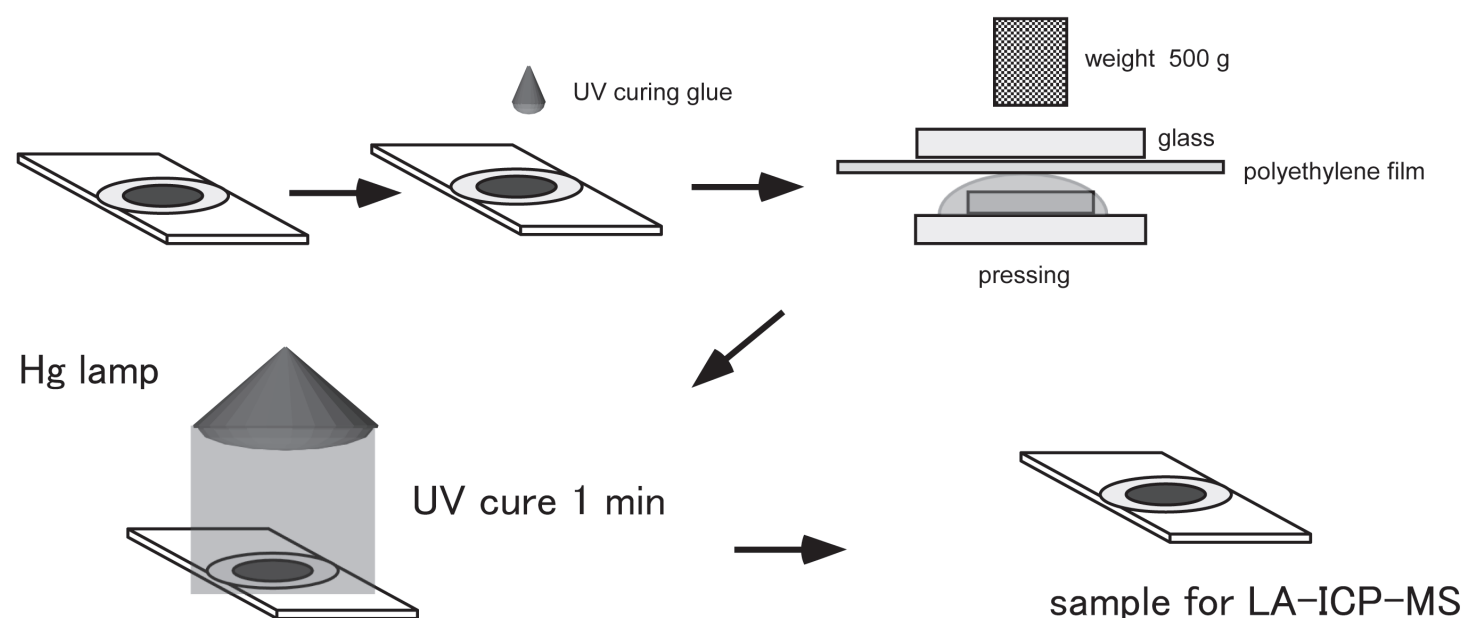

Fig. 2. A schematic diagram of the procedure of the sample preparation for the LA-ICP-MS analysis.
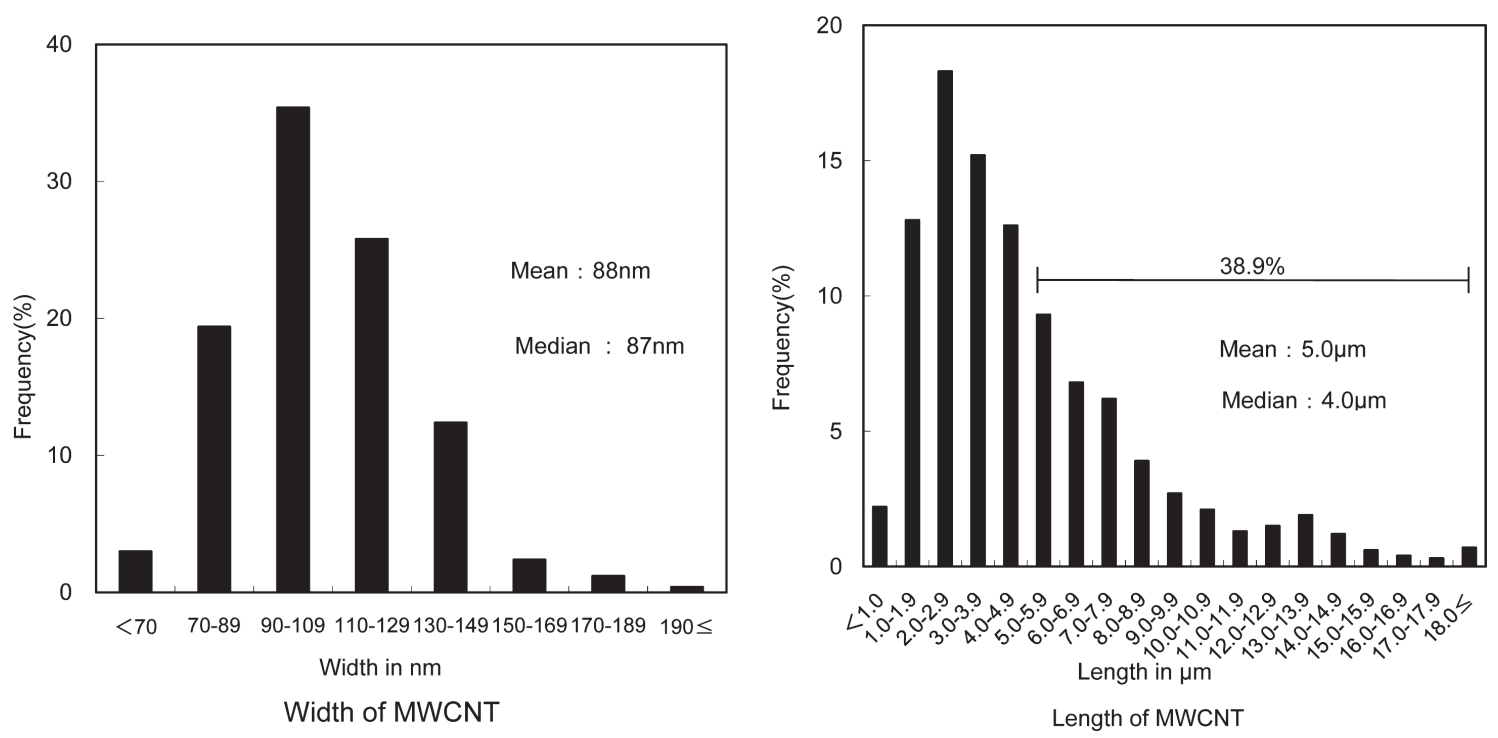

Fig. 3. Histograms of length (A) and width (B) of MWCNT fibers as measured with a curvimeter and a scale loupe, respectively, on the enlarged photographs of SEM image. 


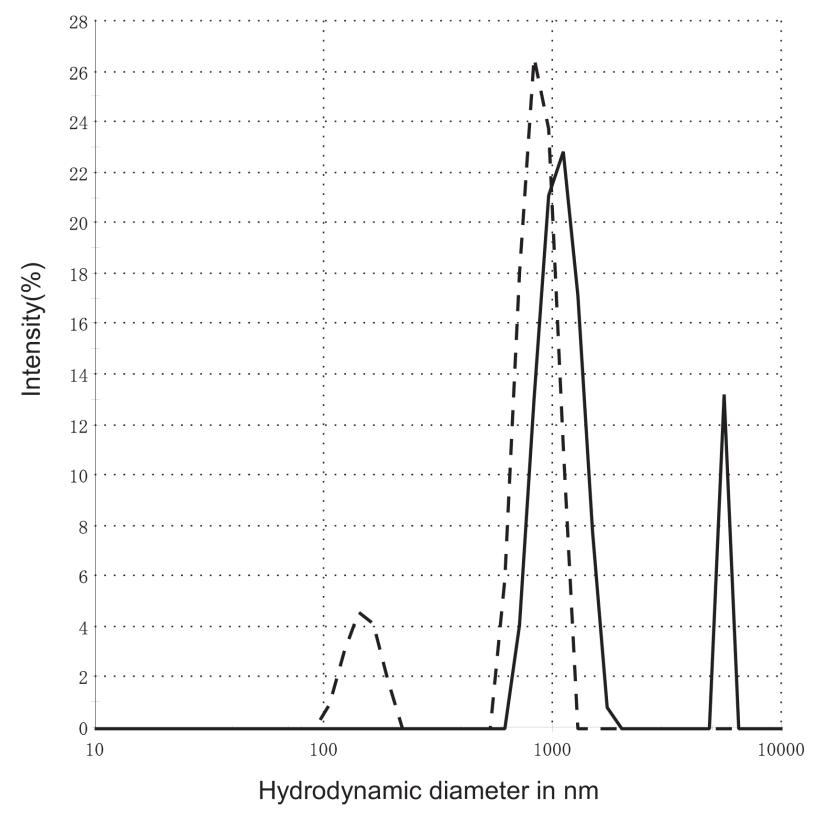

Fig. 4. Effect of ultrasonication on dispersion of MWCNT in the PBS suspension in the presence of $0.1 \%$ Tween 80 as a dispersant. The concentration of MWCNT in the suspension was fixed at $533 \mu \mathrm{g} / \mathrm{ml}$. The solid line indicates the suspension without ultrasonication, while the dashed line represents the sample ultrasonicated for $5 \mathrm{~min}$.

the MWCNT suspension without forming droplets at the tip. Figure 5B shows that the well-dispersed state of MWCNT fibers was maintained at the time of intratracheal instillation in the same manner as in the suspension before the instillation. A SEM image (Fig. 5C) reveals that MWCNT fibers were well-dispersed in the alveoli on Day 1 after instillation, and that the dispersed fibers appear to be penetrated from the cytoplasm of alveolar macrophages after phagocytosis or incomplete phagocytosis.

\section{Metal impurities in the MWCNT}

The qualitative analysis by LA-ICP-MS revealed that the MWCNT contained nickel, cobalt, iron, manganese and chromium. The AAS analysis showed that the contents of iron, chromium and nickel in MWCNT were 4,400, 48 and $17 \mathrm{ppm}(\mathrm{wt} / \mathrm{wt})$, respectively, and that the manganese and cobalt contents were below the quantitative detection limit of $6 \mathrm{ppm}$.

\section{Discussion}

\section{Length and width of MWCNT fibers}

The lengths and widths of MWCNT fibers measured in the present study are in good agreement with those reported by Takagi et $a l^{1}$. The fraction of fiber lengths exceeding $15 \mu \mathrm{m}$ were apparently greater in the
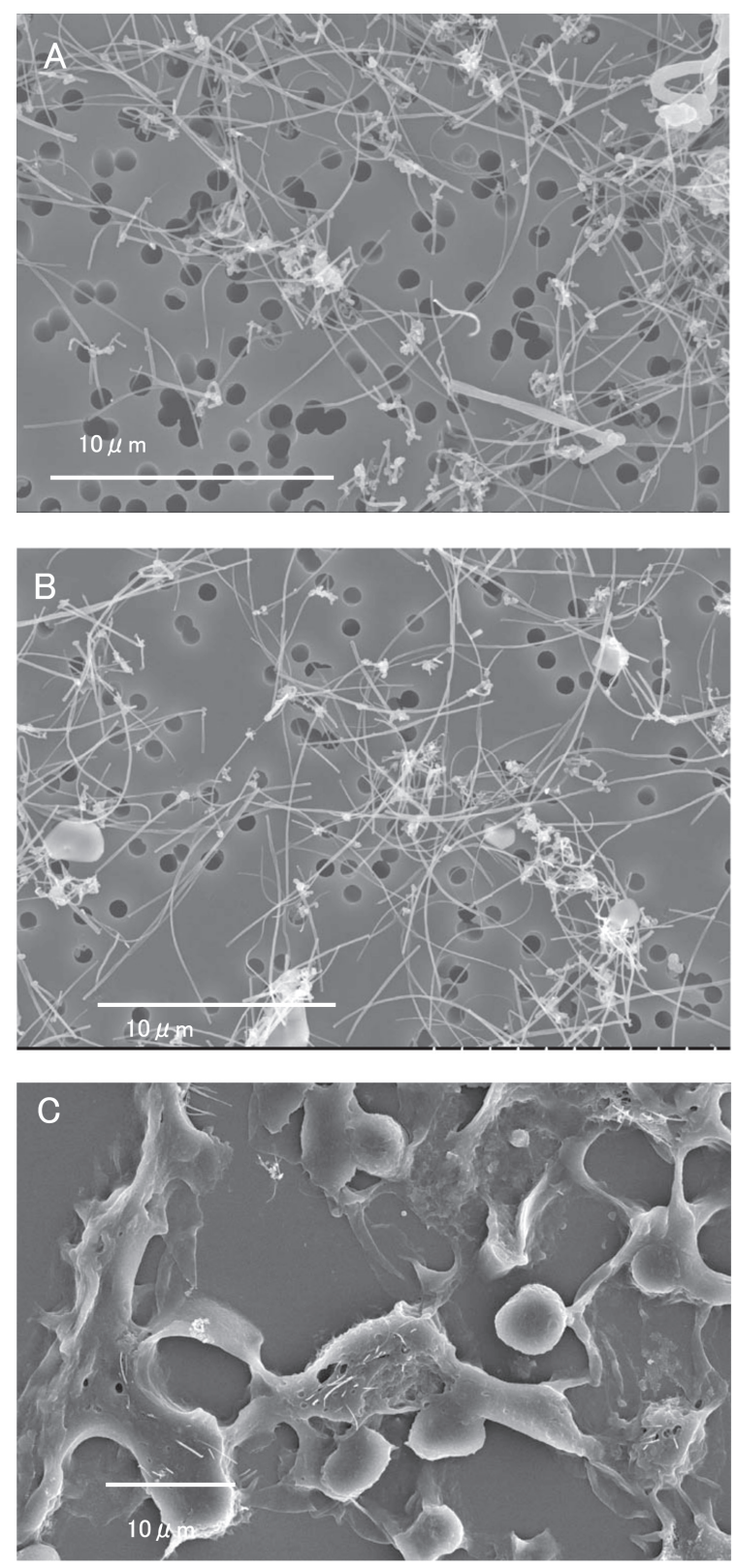

Fig. 5. SEM images of the MWCNT fibers, in the PBS-Tween 80 suspension, showing good dispersion of the fibers in the PBS-Tween 80 suspension after the 5-min ultrasonication (A), in the aerosolized MWCNT suspension ejected into air from the tip of the microspray cannula used for intratracheal instillation (B), and in the alveolar macrophages incompletely engulfing the well-dispersed MWCNT fibers in the alveoli of a rat lung on Day 1 after instillation of $160 \mu \mathrm{g}$ MWCNT (C).

The concentration of MWCNT suspension used here was $533 \mu \mathrm{g} / \mathrm{ml}$ for samples A and B.

MWCNT used in the study of Poland et al. ${ }^{3)}$ than in the present study. Since we used the same MWCNT manufactured by Mitsui \& Co. Ltd, there might be a difference in the measurement method of fiber length between the present study and that Poland et al.'study ${ }^{3}$. 
Indeed, we measured fibers greater than $0.5 \mu \mathrm{m}$ in length on enlarged SEM photoprints. The present data of length and width of MWCNT fibers suggest that MWCNT might stimulate asbestos-like, lengthdependent, pathogenic behavior in the lung. Poland et $a l .{ }^{3)}$ demonstrated that long MWCNT fibers peritoneally injected in the abdominal cavity of female mice exert asbestos-like pathogenicity such as frustrated phagocytosis. Indeed, physical dimensions such as length and width of biopersistent fibers are known to be critically important determinants for the induction of mesotheliomas ${ }^{15,16)}$. Indeed, the length of asbestos fibers is known to be a critically important determinant for asbestos-induced carcinogenesis ${ }^{14,15)}$. In vitro exposure of cultured LLC-MK 2 cells to long crocidolite asbestos fibers was reported to induce formation of binucleated cells leading to polyploidy, resulting from sterical blocking of cytokinesis by long fibers ${ }^{17)}$. Another key factor for pathogenic, asbestos-like behavior is whether MWCNT is persistent in the lung and pleural cavity in the same manner as in the case of asbestos fibers suggested by Donaldson and $\operatorname{Tran}^{18)}$. Our separate paper ${ }^{10)}$ demonstrated that a single intratracheal instillation of well-dispersed MWCNT fibers in rats caused persistent deposition of MWCNT in the alveolar space and wall, in addition to a tendency of MWCNT deposition in the bronchus-associated lymphoid tissue to gradually increase after the instillation. Those results suggest that the MWCNT is persistent in the lung and pulmonary lymphatic vessels. Therefore, it can be inferred that different pulmonary toxicities might be manifested, depending on the length of MWCNT fibers and their biopersistence. A further study with long-term observation will be needed to examine the biopersistence of MWCNT in the lung and pleura.

\section{Dispersion of MWCNT fibers in the suspension and in the lung tissue}

Together with addition of Tween 80 into PBS, 5-min ultrasonication was found to facilitate good dispersion of the agglomerated MWCNT fibers in the suspension. Since Tween 80 was reported to increase the susceptibility to oxidative stress in rat thymocytes at $10-30 \mu \mathrm{g} / \mathrm{ml}$ under in vitro conditions ${ }^{19)}$, the concentration of Tween 80 used in the present study was fixed at a concentration of $0.1 \%$, in order to keep good dispersion and to minimize the pulmonary toxic responses to Tween 80 . In our intratracheal instillation study ${ }^{10)}$, MWCNT was suspended in the PBS containing $0.1 \%$ Tween 80 and ultrasonicated for $20 \mathrm{~min}$ with an ultrasonic homogenizer. Then, the ultrasonicated suspension of MWCNT was further subjected to additional ultrasonication for $30 \mathrm{~s}$ with a sonicator immediately before intratracheal instillation. This repeated ultrasonication was performed to maintain good dispersion of MWCNT in the suspension, because the MWCNT appeared visually to re-agglomerate when the suspension was left for about $30 \mathrm{~min}$ during the period for intratracheal instillation.

It is interesting to note in the present SEM observation (Fig. 5A) that some MWCNT fibers were overlapped and twisted with each other, but there were neither clumped nor aggregated particles. Besides, knot-like blocks at the ends of fibers were observed occasionally. Presumably, formation of the knot-like structure might be causally related to the presence of residual catalyst particles on which two or more filaments of MWCNTs grow during the gaseous CVD process. The simulation experiment (Fig. 1) revealed that the microspray cannula used in the present study would allow delivery of the MWCNT suspension as a mist-like colloid into the distal end of the trachea, as evidenced by the well-dispersed state of MWCNT fibers (Fig. 5B) similar to that seen in the suspension before the instillation. The SEM observation (Fig. 5C) evidenced that MWCNT fibers were well-dispersed in the alveoli on Day 1 after intratracheal instillation at a dose of $160 \mu \mathrm{g} / \mathrm{rat}$. Notably, cytoplasmic penetration of the dispersed MWCNT fibers after phagocytosis by alveolar macrophages (Fig. 5C) could be categorized as frustrated and incomplete phagocytosis, as proposed by Poland et $a l .{ }^{3)}$ and Hubbs et al. ${ }^{20)}$, respectively. Therefore, it can be concluded from both DLS measurement and SEM observation that the MWCNT fibers were welldispersed in the suspension by 20-min ultrasonication in the presence of $0.1 \%$ Tween 80 as a dispersant.

Dispersion or agglomeration of SWCNT administered by intratracheal instillation and pharyngeal aspiration has been reported to affect the pulmonary toxic responses. Warheit et al. $\left.{ }^{6}\right)$ reported that intratracheal instillation of SWCNT produced mortality due to suffocation in $15 \%$ of the dosed rats, resulting from mechanical blockage of the respiratory tract by SWCNT which was highly electrostatic and did not disperse into single fibers. Mercer et $a l .{ }^{5)}$ reported that pharyngeal aspiration of welldispersed SWCNT in mice induced a potent interstitial fibrotic reaction with wide distribution of the dispersed fibers into the alveolar interstitium in the absence of granuloma formation. On the other hand, Shvedova et $a l .{ }^{9)}$ showed that pharyngeal aspiration of agglomerated, less-dispersed SWCNT in mice induced granulomatous lesions associated with hypertrophied epithelial cells surrounding SWCNT aggregate as well as inflammation and interstitial fibrosis. Taken together, it can be inferred that good dispersion of MWCNT fibers in the suspension and ultimately in the lung tissue might be involved in the rat pulmonary lesions induced by intra- 
tracheal instillation of MWCNT pretreated in the same manner ${ }^{10)}$.

\section{Metal impurities}

MWCNT iron, chromium and nickel contents were 4,400, 48 and $17 \mathrm{ppm}(\mathrm{wt} / \mathrm{wt})$ in the present study. They were estimated to be equivalent to lung burden of $0.7,0.0077$ and $0.0027 \mu \mathrm{g} / \mathrm{rat}$, respectively, when $160 \mu \mathrm{g}$ of MWCNT were intratracheally instilled. We examined the pulmonary toxic responses to these metal impurities on the basis of a literature survey. Toya $e t$ $a l^{21,22)}$ reported that intratracheal instillation of chromium and nickel fumes in rats induced a slight degree of pulmonary lesions at doses of $3.4 \mathrm{mg} \mathrm{Cr} / \mathrm{kg}$ and $1.4 \mathrm{mg} \mathrm{Ni} / \mathrm{kg}$ body weight. It can be inferred on the basis of these reported findings that the administration of 0.0077 and $0.0027 \mu \mathrm{g} / \mathrm{rat}$, which are equivalent to 0.031 and $0.011 \mu \mathrm{g} / \mathrm{kg}$ body weight, would not induce any pulmonary lesions. Shvedova et al. ${ }^{7)}$ reported that in vitro exposure of human keratinocyte cells to unrefined SWCNT containing 30\% iron produced cellular toxicity and oxidative stress as detected by the electron spin resonance (ESR) of the iron. Kagan et al. ${ }^{8)}$ reported that iron-rich SWCNT $(26 \% \mathrm{Fe})$ caused significant loss of intracellular low molecular thiols (GSH) and accumulation of lipid hydroxides in both zymosan- and PMAstimulated RAW 264.7 macrophages as compared with iron-stripped SWCNT $(0.23 \% \mathrm{Fe})$. Shvedova et al. ${ }^{9)}$ also showed that pharyngeal aspiration of the purified SWCNT containing $0.23 \%$ iron in mice at a dose of $40 \mu \mathrm{g} /$ head (equivalent to $0.09 \mu \mathrm{g}$ iron) did not generate detectable signals from iron paramagnetic centers readily detectable by ESR spectroscopy in the unrefined SWCNT. Assuming similar distribution of 0.7 $\mu \mathrm{g}$ iron in the present study and $0.09 \mu \mathrm{g}$ iron in the study of Shvedova et al. over the alveolar epithelial surface area, and normalizing to the equivalent alveolar epithelial surface area in rats $\left(0.392 \mathrm{~m}^{2} / \mathrm{lung}\right)$ and mice $\left(0.068 \mathrm{~m}^{2} / \mathrm{lung}\right)$ from a published morphometric analy$\mathrm{sis}^{21)}$, the amount of iron in the unit alveolar epithelial surface area would be $1.7 \mu \mathrm{g} / \mathrm{m}^{2}$ for rats and $1.3 \mu \mathrm{g} / \mathrm{m}^{2}$ for mice. Taking the results of the in vitro and in vivo studies by Shvedova et al. and Kagan et al. ${ }^{7-9)}$ into consideration, any pulmonary responses to $4,400 \mathrm{ppm}$ iron in the MWCNT might not contribute significantly to the observed pulmonary responses to $160 \mu \mathrm{g}$ MWCNT. It can be concluded that $4,400 \mathrm{ppm}(\mathrm{wt} / \mathrm{wt})$ iron, $48 \mathrm{ppm}$ chromium and $17 \mathrm{ppm}$ nickel in the MWCNT were below the levels that would elicit positive pulmonary toxic responses to these metals.

\section{Conclusion}

Length and width of MWCNT fibers, dispersion of MWCNT in the PBS suspension containing $0.1 \%$ Tween 80 after ultrasonication, and metal impurities of MWCNT were investigated for an intratracheal instillation study. Mean length and width of single MWCNT fibers as measured on SEM photographs were $5.0 \mu \mathrm{m}$ and $88 \mathrm{~nm}$, respectively, and the fibers longer than $5.0 \mu \mathrm{m}$ were $38.9 \%$ of all fibers measured. Both DLS measurement and SEM observation revealed that the MWCNT was well-dispersed in the suspension, at the time of intratracheal instillation, and in the alveoli on Day 1 after instillation. The AAS analysis showed that MWCNT iron, chromium and nickel contents were 4,400, 48 and $17 \mathrm{ppm}(\mathrm{wt} / \mathrm{wt})$, respectively, all of which were below the levels that would elicit positive pulmonary toxic responses to these metals.

\section{Acknowledgements}

The present study was financially supported by a Grant-in-Aid for Scientific Research from the Ministry of Health, Labour and Welfare of Japan. The authors are deeply indebted to Dr. Haruhiko Sakurai, Professor Emeritus of Keio University, for his fruitful discussion in the present study and to Dr. Makoto Ohnishi of the JBRC for his excellent assistance with metal analysis in MWCNT.

\section{References}

1) Takagi A, Hirose A, Nishimura T, Fukumori N, Ogata A, Ohashi N, Kitajima S, Kanno J (2008) Induction of mesothelioma in $\mathrm{p} 53+/-$ mouse by intraperitoneal application of multi-wall carbon nanotube. J Toxicol Sci 33, 105-16.

2) Sakamoto Y, Nakae D, Fukumori N, Tayama K, Maekawa A, Imai K, Hirose A, Nishimura T, Ohashi N, Ogata A (2009) Induction of mesothelioma by a single intrascrotal administration of multi-wall carbon nanotube in intact male Fischer 344 rats. J Toxicol Sci 34, 65-76.

3) Poland CA, Duffin R, Kinloch I, Maynard A, Wallace WAH, Seaton A, Stone V, Brown S, MacNee W, Donaldson K (2008) Carbon nanotubes introduced into the abdominal cavity of mice show asbestos-like pathogenicity in a pilot study. Nat Nanotechnol 3, 423-8.

4) Driscoll KE, Costa DL, Hatch G, Henderson R, Oberdörster G, Salem H, Schlesinger RB (2000) Intratracheal instillation as an exposure technique for the evaluation of respiratory tract toxicity: uses and limitations. Toxicol Sci 55, 24-35.

5) Mercer RR, Scabilloni J, Wang L, Kisin E, Murray 
AR, Schwegler-Berry D, Shvedova AA, Castranova V (2008) Alteration of deposition pattern and pulmonary response as a result of improved dispersion of aspirated single-walled carbon nanotubes in a mouse model. Am J Physiol Lung Cell Mol Physiol 294, L87-L97.

6) Warheit DB, Laurence BR, Reed KL, Roach DH, Reynolds GAM, Webb TR (2004) Comparative pulmonary toxicity assessment of single-wall carbon nanotubes in rats. Toxicol Sci 77, 117-25.

7) Shvedova AA, Castranova V, Kisin ER, SchweglerBerry D, Murray AR, Gandelsman VZ, Maynard A, Baron P (2003) Exposure to carbon nanotube material: assessment of nanotube cytotoxicity using human keratocyte cells. J Toxicol Environ Health A 66, 1909-26.

8) Kagan VE, Tyurina YY, Tyurin VA, Konduru NV, Potapovich AI, Osipov AN, Kisin ER, SchweglerBerry D, Mercer R, Castranova V, Shvedova AA (2006) Direct and indirect effects of single walled carbon nanotubes on RAW264.7 macrophages: role of iron. Toxicol Lett 165, 88-100.

9) Shvedova AA, Kisin ER, Mercer R, Murray AR, Johnson VJ, Potapovich AI, Tyurina YY, Gorelik O, Arepalli S, Schwegler-Berry D, Hubbs AF, Antonini J, Evans DE, Ku BK, Ramsey D, Maynard A, Kagan VE, Castranova V, Baron P (2005) Unusual inflammatory and fibrogenic pulmonary responses to singlewalled carbon nanotubes in mice. Am J Physiol Lung Cell Mol Physiol 289, L698-L708.

10) Aiso S, Yamazaki K, Umeda $Y$, Asakura M, Takaya M, Toya T, Koda S, Nagano K, Arito H, Fukushima S (2010) Pulmonary toxicity of intratracheally instilled multi-wall carbon nanotubes in male Fischer 344 rats. Ind Health (in press).

11) Nano Carbon Thechnologies Co., LTD. The manufacturing process of MWCNT. http://www.nikkiso. co.jp/rd/main/014.html. (in Japanese) Accessed June 25, 2009.

12) Nikkiso Co., LTD. Development of arbon nanotube process in the nanotechnology world. http://www. nikkiso.co.jp/rd/main/014.html. (in Japanese) Accessed June 25, 2009.

13) Takaya M, Kohyama N, Serita F, Shinohara Y, OnoOgasawara M, Otaki N, Toya T, Takata A (2002). Analysis and biological effects of airborne rare-earth particles from functional materials. In: Kankyouhozen Kenkyuseikashu III. Japan Ministry of the Environment, Tokyo (in Japanese).

14) Morrow PE (1988) Possible mechanisms to explain dust overloading of the lungs. Fundam Appl Toxicol 10, 369-84.

15) Pott F (1978) Some aspects on the dosimetry of the carcinogenic potency of asbestos and other fibrous dusts. Staub-Reinhalt Luft 38, 486-90.

16) Stanton MF, Layard M, Togeris A, Miller E, May M, Morgan E, Smith A (1981) Relation of particle dimension to carcinogenicity in amphibole asbestos and other fibrous minerals. J Natl Cancer Inst 67, 965-75.

17) Jensen CG, Jensen LCW, Rieder CL, Cole RW, Ault JG (1996) Long crocidolite asbestos fibers cause polyploidy by sterically blocking cytokinesis. Carcinogenesis 17, 2013-21.

18) Donaldson K, Tran CL (2004) An introduction to the short-term toxicology of respirable industrial fibres. Mutat Res 553, 5-9.

19) Tatsuishi T, Oyama Y, Iwase K, Yamaguchi J, Kobayashi M, Nishimura Y, Kanada A, Hirama S (2005) Polysorbate 80 increases the susceptibility to oxidative stress in rat thymocytes. Toxicology 207, 7-14.

20) Hubbs A, Mercer RR, Coad JE, Barrelli LA, Willard PA, Sriram K, Wolfarth M, Castranova V, Porter D (2009) Persistent pulmonary inflammation, airway mucous metaplasia and migration of multiwalled carbon nanotubes from the lung after subchronic exposure. The Toxicologist (48th Annual Meeting of SOT) 457.

21) Toya T, Fukuda K, Kohyama N, Kyono H, Arito H (1999) Hexavalent chromium responsible for lung lesions induced by intratracheal instillation of chromium fumes in rats. Ind Health 37, 36-46.

22) Toya T, Serita F, Sawatari K, Fukuda K (1997) Lung lesions induced by intratracheal instillation of nickel fumes and nickeloxide powder in rats. Ind Health 35, 69-77.

23) Pinkerton KE, Gehr P, Crapo JD (1991) Architecture and cellular compositiom of the air-blood barrier. In: Treatise on pulmonary toxicology. Vol. 1. Comparative biology of the normal lung, Parent RA (Ed.), 121-8, CRC Press, Boca Raton. 